\title{
Formation and disintegration of the Antarctic ice sheet
}

\author{
PhilipPe HLYbRechts \\ Alfred-Wegener-Institut für Polar- und Meeresforschung, D-27515 Bremerhaven, Germany, and \\ Geografisch Instituut, Vrije Universiteit Brussel, B-10.50 Brussels, Belgium
}

\begin{abstract}
A model of the Antarctic ice shect has been used to simulate the ice sheet in warmer climates, in order to investigate what kind of ice-sheet geometries one can reasonably expect under what kind of climatic conditions and to discover which physical mechanisms may be involved to explain them. The results of these experiments reveal the considerable stability of, in particular, the East Antarctic ice sheet. It would require a tempcrature risc of between 17 and $20 \mathrm{~K}$ above present levels to remove this icc sheet from the subglacial basins in the interior of the continent and of $25 \mathrm{~K}$ to melt down the Antarctic ice sheet completely. For a temperature rise below $5 \mathrm{~K}$, the model actually predicts a larger Antarctic ice sheet than today as a result of increased snowfall, whereas the West Antarctic ice sheet was found not to survive temperatures more than $8-10 \mathrm{~K}$ above present values. Furthermore, basal temperature conditions in these experiments point to the problems involved in raising the base of the icc sheet to the pressurc-melting point over the large areas neccssary to consider the possibility of sliding instability. These results bear on a lively debate regarding the late Cenozoic glacial history of Antarctica. Particularly, based on these findings, it is difficult to reconcile a highly variable East Antarctic ice sheet until the Pliocene with modest warming recorded in, for instance, the deep-sea records for the late Neogene.
\end{abstract}

\section{INTRODUGTION}

The Antarctic ice sheet is by far the largest glacicr system on Earth. At present, air temperatures are so low that surface melting and run-off are virtually negligible, and the ice sheet loses its mass primarily by calving of iccbergs and basal melting beneath ice shelves. Under these conditions, the size of the ice sheet is mainly limited by the depth of the surrounding ocean. Despite this apparent robustness, the potential behaviour of the ice sheet in a warmer climate is a matter of great concern. In the late 1970 s, it was stressed several times that the West Antarctic ice sheet, with its buttressing ice shelves and its bed so far below sea level, could be so inherently unstable that a moderate warming may lead to a runaway situation in which the major part of the West Antarctic icc sheet disintegrates in a few centuries time. Though this view is nowadays regarded as probably too dramatic (e.g. Van der Vecn, 1985; Huybrechts and Oerlemans, 1990), the possibility of unstable behaviour, perhaps linked to climate in an indirect way, is still a potential option (MacAyeal, 1992). Bccause of its terrestrial nature, the Fast Antarctic ice sheet, on the other hand, is widely belicved to be less vulnerable to a climatic warming.

Nevertheless, new interest in the stability of the East Antarctic ice sheet was recently stirred by controversies over its late-Tertiary glacial history. The established view is that the East Antarctic ice sheet grew to its full extent somewhere between 14 and $11 \mathrm{Ma}$ ago, and remained a stable and permanent feature exhibiting some changes in volume since then (Kennett, 1977; Denton and others,
1990; Sugden, 1992; Marchant and others, 1993). 'This "stabilist view" is now being challenged by the discovery of marine diatoms in the Sirius Group in the Transantarctic Mountains. Their presence has been interpreted as indicating that these diatoms were living in marine basins in the interior of East Antarctica, and that these basins were subsequently covered by an expanding icc sheet that over-rode the Transantarctic Mountains and transported the diatoms to their present locations (Webb and others, 1984; Webb and Harwood, 1991). Based on the ages of the diatoms, the latest episode of a largely icefree continent would have occurred as recently as the mid- to late Pliocene about $3 \mathrm{Ma}$ ago, when the climate was only slightly warmer than it is today (Harwood, 1986; Barrett and others, 1992). This highly unstable behaviour has led to the suggestion that the East Antarctic ice sheet is very sensitive to global warming and could again largely disappear in the near future if global temperatures increased by a few degrees. The implications would be far-reaching: if melted, the East Antarctic ice sheet would raise world-wide sea levels by around $60 \mathrm{~m}$.

In this paper, I investigate the climatic conditions under which the Antarctic ice sheet may form and disintegrate, and calculate how the corresponding ice sheets may have looked. In order to do this, I use a threedimensional thermomechanical model for the entire Antarctic ice sheet in conncction with simple massbalance considerations. Though the emphasis is on the responsc of the terrestrial East Antarctic ice sheet, this study also yields details on how the West Antarctic ice shect would react to a warmer surface climate. 


\section{MODEL SET-UP}

The model is basically similar to the one used to study the Antarctic ice sheet on a glacial-interglacial and a greenhouse-warming time-scale (Huybrechts, 1990; Huybrechts and Oerlemans, 1990), except that an explicit calculation of grounding-line dynamics and ice-shelf flow was not made. Instead, the present grounding-line position was considered as a limit for the maximum icesheet cxtent, bcyond which all ice is lost to the ocean. Expansion of grounded ice over terrain below sea level is therefore still possible, but is entirely controlled by the surface mass balance and the ability of the ice shect to extend down to sea level. In effect, all ice is treated as grounded ice, irrespective of the bed elcvation with the understanding that it cannot expand beyond its present limits. This approach to modelling the boundary ice is not considered a serious problem, since the ice sheet will, in a warmer climate, retreat on to the East Antarctic continent and will no longer interact with the ocean directly. Also, the greenhouse-warming experiments reported by Huybrechts and Oerlemans (1990) did not show any appreciable scaward movcment of the grounding line, not even for a small warming. Other than that, there are no modifications to the original ice-dynamics model, that is, the model basically solves coupled equations for ice flow and ice temperature on a $40 \mathrm{~km}$ grid with 11 layers in the vertical and includes such features as basal sliding and isostatic adjustments of the bedrock. The structure of the model is shown in Figure 1.

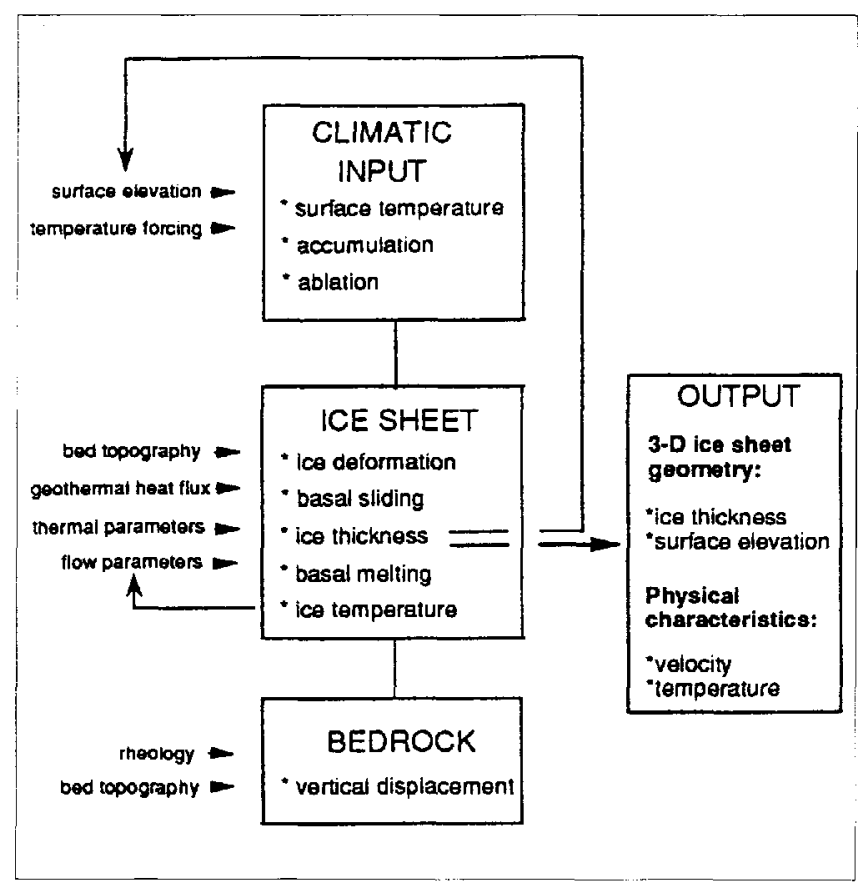

Fig. 1. Structure of the model used in this study. The model inputs are shown on the lefthand side. A prescribed lemperature change drives the model, which has grounded ice and bedrock adjustment as major components. Ice thickness feeds back on surface elevation, an important parameter for the calculation of the climatic input. The main output consists of the fully coupled temperature and velocity fields and the three-dimensional ice-sheet geometry, which is freely generated by the model.
The primary input to the model, besides the bedrock topography, is the mass balance at any time and place in the modcl domain. Using data from Orvig (1970) and following analyses by Giovinetto and others (1990) and Fortuin and Oerlemans (1990), climatic-boundary conditions are parametcrized as:

$$
\begin{aligned}
& \text { TMA }=34.46-0.00914 H_{\text {sur }}-0.68775 \text { lat }+T_{\text {for }} \\
& \text { TMS }=16.81-0.00692 H_{\text {sur }}-0.27937 \text { lat }+T_{\text {for }} \\
& \text { ACC }=0.78+2.525 \times 10^{-2} \mathrm{TMA}+2.225 \times 10^{-1} \mathrm{TMA}^{2}
\end{aligned}
$$

where TMA (in ${ }^{\circ} \mathrm{C}$ ) is the mean annual surface air temperature, taken to represent the ice temperature at $10 \mathrm{~m}$ depth, $H_{\text {sur }}$ is surface elevation in metres above sea level, lat is latitude in "S and $T_{\text {for }}$ is the applied temperature change with respect to present conditions. $\mathrm{ACC}$ (in $\mathrm{ma}^{-1}$ ice equivalent) is the accumulation rate and gives a reasonable fit to the presently obscrved snowfall distribution. It varies from as little as $5 \mathrm{~cm} \mathrm{a}^{1}$ for a minimum air temperature of $-56^{\circ} \mathrm{C}$ to around $0.5 \mathrm{~m} \mathrm{a}^{-1}$ for a mean annual temperalure of $-12^{\circ} \mathrm{C}$. Its parameterization has palaeoclimatic validity, if one accepts that temperature remains the main controlling factor for precipitation, also in past environments. TMS (in ${ }^{\circ} \mathrm{C}$ ) is the summer temperature needed to determine the annual temperature cycle in the ablation model, which is bascd on the degrec-day method and makes a distinction between ice and snow melting (Braithwaite and Olesen, 1989). This method of determining glacier run-off is similar to the procedure adopted in Huybrechts and others (1991), where it was used with some success in determining ablation rates on the Greenland ice sheet. The latter can be considered as the modern analogue for an (East) Antarctic ice sheet in a climate warmer by $10-$ $15 \mathrm{~K}$ in the annual mean. Additional features, such as superimposed ice formation and the fraction of precipitation falling as rain, of importance for the present-day ice sheets in Greenland and the Canadian Arctic, have been disregarded simply because uncertainties in the other climatic-boundary conditions would not justify such a degree of sophistication.

\section{RESULTS}

Figure 2 shows the calculated ice-shect geometries for a tempcrature range of between 5 and $20 \mathrm{~K}$ above present levels. For a tcmperature increase of up to $5 \mathrm{~K}$, the icesheet geometry is quite stable. There is a slight retreat of ice along the northernmost tip of the Antarctic Peninsula and elevations tend to rise a littlc over the interior of the continent, but the overall form of the ice sheet exhibits only minor changes. This is because melting at the margin is not yet of sufficient strength to form an ablation area of any significance along the coast. The formation of such an ablation area, in which run-off exceeds accumulation on an annual basis, is a necessary pre-condition for the ice sheet to recede over its continental base. In addition, the thickening effect of increased accumulation rates is counteracted in central areas by thinning associated with the warmer and softcr ice. This is very similar to the behaviour reported for the Antarctic ice sheet during a glacial-interglacial contrast, where eustatic sea-level 

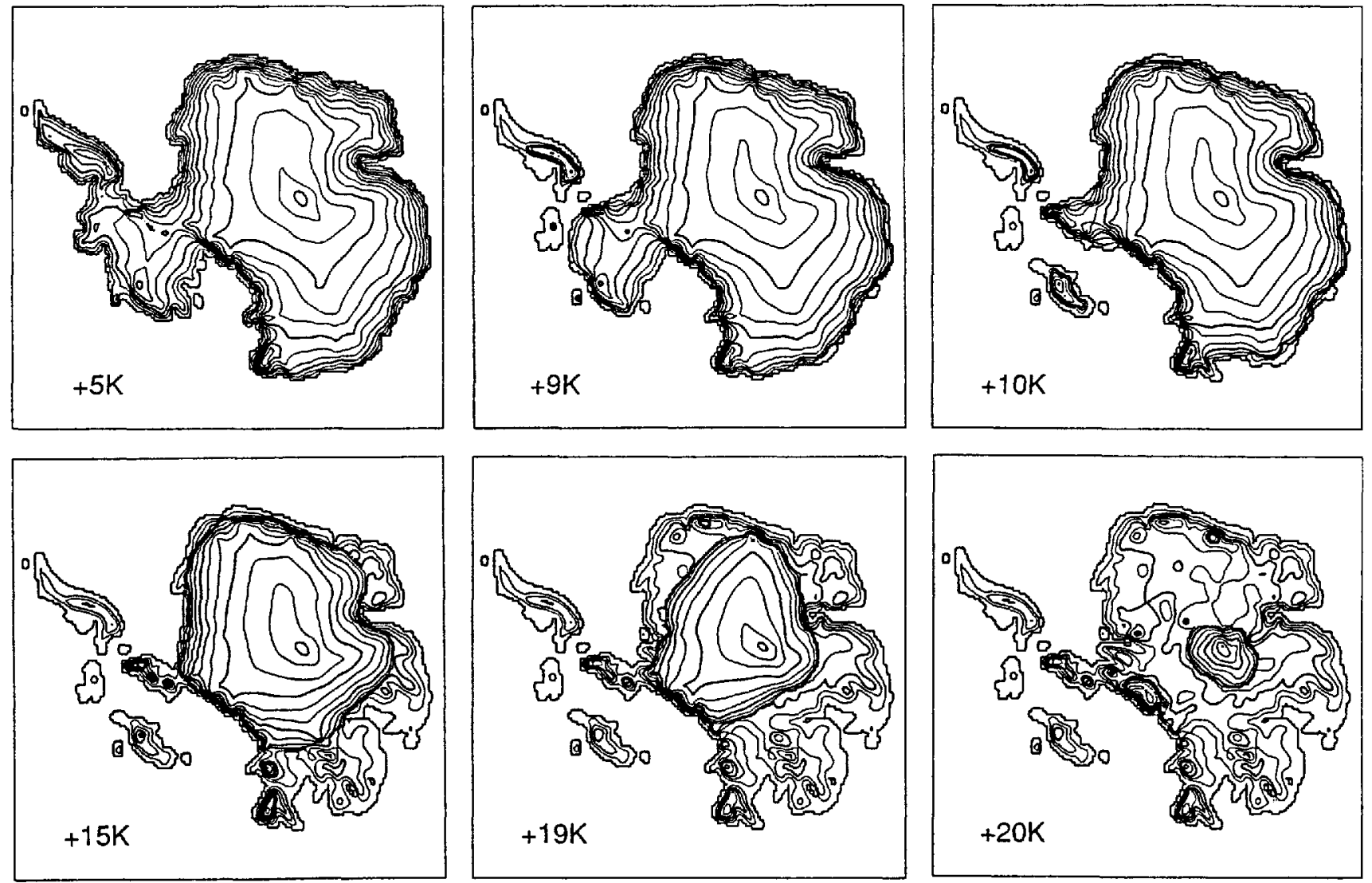

Fig. 2. Steady-state ice-sheet geometries for temperature perurbations aboze present levels as indicated. liolines are for surface elevation. Contour interval is $333 \mathrm{~m}$ and the thick lines are for every $1000 \mathrm{~m}$. These experiments started with the present ice sheet as an inilial configuration.

changes rather than climatic changes were found to be the most decisive factor controlling fluctuations of the ice sheet (Huybrechts, 1990).

A first threshold is crossed for a warming in the range of $8-10 \mathrm{~K}$. For a temperature rise of $+9 \mathrm{~K}$, most of the ice cover over the Antarctic Peninsula has retreated to the high central mountain ridge and the peninsula ice cap has become uncoupled from the West Antarctic ice sheet. This leads to an open seaway between Palmer Land and Ellsworth Land. For a warming of betwecn 9 and $10 \mathrm{~K}$, the mass balance over most of West Antarctica has become sufficiently negative at sea level, so that grounded ice is no longer able to feed an ice shelf. This starts a chain of reactions that ultimately results in the almost total destruction of the marine parts of the West Antarctic icc sheet. The mechanism called upon for ice-sheet decay does not involve direct interaction with the ocean but is due to the height-mass-balance feed-back: melting of the West Antarctic ice sheet at its margin leads to a shrinking base and thus lower elevations, which then further enlarges the ablation area and so on. Since the effects of basal melting and icc-shelf thinning on grounding-line movements arc not included, this $+9-10 \mathrm{~K}$ value should probably be considered as an upper bound for West Antarctic ice-sheet destruction. Nevertheless, though invoking an alternative mechanism, it is interesting to see that the model confirms that the West Antarctic ice sheet cannot survive without its ice shelves. For a warming of around $10 \mathrm{~K}$, the ice sheet also starts to retreat from the continental margin in East Antarctica and ice shclves cease to cxist altogether.
As shown in the bottom series of graphs in Figure 2. the Antarctic ice sheet starts to retreat more seriously for temperature rises above $15 \mathrm{~K}$, when local ice caps appear in Victoria Land and the Ellsworth Mountains which are disconnected from the main ice shect. A second threshold, now associated with the East Antarctic ice sheet, is crossed for temperatures in the range of $+19-20 \mathrm{~K}$. At this stage, the East Antarctic ice sheet has basically disintegrated into two icc caps situated on top of the Transantarctic and the Gamburtsev Mountains. A small ice cap also survives in the Sor-Rondane mountains, which acts as a third inception area. The presence of these mountains explains why the East Antarctic ice sheet is able to resist a much larger warming than the West Antarctic ice sheet for a similar latitude, because thesc mountains enable the ice sheet to retreat to higher ground. It is also intercsting to note that an ice-frec corridor centered over the Pensacola Basin, where marine sedimentation could take place, is only produced when the ice sheet as a whole has almost entirely disappeared.

Another important characteristic for ice-sheet dynamics is the cxtent of basal melting, because the presence of liquid water is a necessary pre-requisite for enhanced basal motion, whether this occurs as basal sliding at the ice-rock interface or by means of a deforming layer of soft sediments. The resulting distribution of arcas at the pressure-mclting point is shown in Figure 3. Interestingly, the present-day pattern of basal melting is quite well conserved and changes in a warmer climate are modest. 

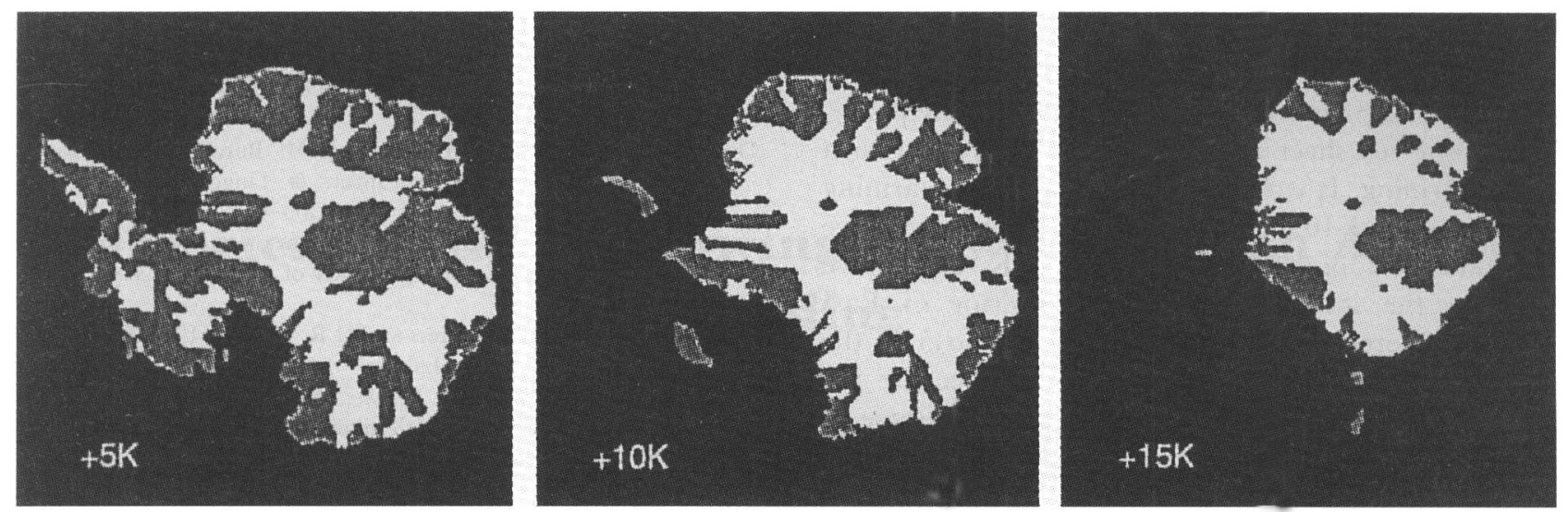

Fig. 3. Basal temperature conditions corresponding to the series of experiments shown in Figure 2. White areas indicate where the base is at the pressure-melting point and basal sliding can occur. These plots demonstrate that mixed wet and cold basal conditions also prevail in warmer climales, much like the situation today.

Though there is some expansion of wet ice, basal melting remains mainly confined to regions with thick ice, whereas the shallower ice covering the Transantaretic and the Gamburtsev Mountains continues to be coldbased. This behaviour is a result of two largely counteracting effects: in a warmer climate, the surface icc becomes warmer but, on the other hand, increased accumulation rates will lead to a more vigorous motion of the icc within the ice shect, so that more cold ice is advected downward. As a result, the steady-state surfaceto-bottom temperature difference is reduced and the ensuing basal warming is only a fraction of the initial surface warming. The implication for the dynamics of the East Antarctic ice sheet is that any instability mechanism invoking widespread basal melting is unlikely to have played a major role in the ice sheet's history.

The results of these experiments are best summarized in a solution diagram giving the equilibrium ice volume as a function of the temperature perturbation (Fig. 4). Two sets of model runs are shown, one in which the present ice sheet was used as an initial condition, and another in which the calculations began from bare rock. Clearly, there are regions with multiple solutions. For certain values of the temperature perturbation, the final state of the ice sheet depends on whether the ice sheet was already present or not. 'This is indicative of hysteresis, though its magnitude is not particularly large. This type of behaviour is due to the fact that an ice sheet creates its own surface climate, so that when the icc shect is removed it needs a colder climate to re-grow to the same size. The region around $9 \mathrm{~K}$ is linked to the threshold for the West Antarctic ice shect, whereas the region between 16 and $20 \mathrm{~K}$ is associated with the East Antarctic ice sheet. Furthermore, the Antarctic ice sheet reaches its largest volume for a climatic warming of around $5 \mathrm{~K}$, when also the surface mass balance reaches a maximum. Above this tempcrature, melting starts to increase faster than the accumulation rate and an ablation area develops around the coast. 'The ice sheet disappears completely for a climate more than $25 \mathrm{~K}$ warmer than today. In that case, there are no regions left in the model domain with a positive surface mass balance. Typical time-scales to reach equilibrium are of the order of a few tens of thousands of years for Antarctic ice-sheet growth and of $5000-10000$ years to melt the ice shect down.
When transposing these results to late-Tertiary environments, onc should of course bear in mind that the topographical and climatic-boundary conditions may have been quite different from today's. For instance, the Transantarctic Mountains may have been substantially less elevated (Webb and others, 1986; McKelvey and others, 1991) or patterns of precipitation and temperature change may have been inlluenced by another gcography, a changed continental configuration or a different condition of the surface (Oglesby, 1989). But, even under the extreme conditions of a flat bedrock and mass-balance parameters stretched to their limits, the ice sheet would still need a temperature rise of the order of $+15 \mathrm{~K}$ to melt down entirely (Huybrechts, 1993).

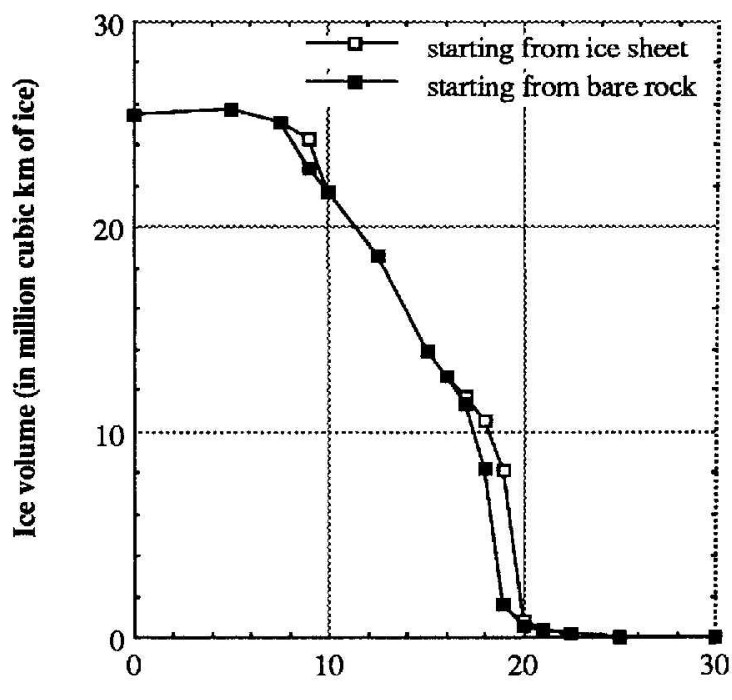

Temperature rise above present level $(K)$

Fig. 4. Solution diagram gizing steady-state ice volume as a function of the temperature perturbation. The solid squares are for model runs in which the initial condition was an ice-free continent, the open squares started from the present ice sheet. Regions with multiple solutions indicate that the resulting ice-sheet geometry depends on its past history. To give an idea of the associated impact on sea level: $1 \times 10^{6} \mathrm{~km}^{3}$ of ice corresponds to a world-wide sealevel change of around $2.5 \mathrm{~m}$. 


\section{CONGLUSION}

According to the model results presented in this paper, the Antarctic ice sheet appears to be very robust to a climatic warming. It would take a temperature warming of between 8 and $10 \mathrm{~K}$ to mclt the West Antarctic ice sheet down and of between 20 and $25 \mathrm{~K}$ to remove completely the ice sheet from the interior of Fast Antarctica. Moreover, for a warming of up to $5 \mathrm{~K}$, the ice sheet would be even larger than today, because the increase in snowfall would still outweigh the increase in surface melting. In addition, massive basal melting, which is the pre-requisite for any instability mechanism invoking the decoupling of the ice shect from its basc, has - not been shown to take place in a warmer climate. Interesting also is that the maintenance of the West Antarctic ice sheet has turned out to be closely linked to the ability of the ice sheet to form an ice shelf, though the mechanism for its removal did not involve direct interaction with the ocean. Instead, the decisive factor for its disintegration was linked to the fact that it cannot retreat to higher ground once its margins are subjected to surface melting and begin to recede.

T'hese results are of special interest in the light of the ongoing debate on the nature and extent of Antarctic glaciation during the late Tertiary. Based on these findings, there are serious climatological and glaciological difficulties associated with a Pliocene disintegration of the East Antarctic ice sheet. The problem is that the only mcchanism able to explain a smaller ice sheet is massive surface melting, and that this requires a temperature rise well in excess of the modest warming recorded in, for instance, the marine-isotope records (e.g. Kennett, 1982). Rather, it is more likely that the Pliocene ice sheet was somewhat larger than today.

\section{ACKNOWLEDGEMENTS}

I wish to thank the Belgian Research Program on Antarctica (Science Policy Office, Services of the Prime Minister) and the Belgian National Fund for Scientific Research (NFWO) for initial support of this study.

\section{REFERENCES}

Barrett, P.J., C. J. Adams, W. C. McIntosh, C. C. Swisher, III and G. S. Wilson. 1992. Geochronological evidence supporting Antarctic deglaciation three million years ago. Nalume, 359/6398), 816-818.
Braithwaite, R.J. and O. B. Olesen. 1989. Calculation of glacier ablation from air temperature, West Greenland. In Oerlemans, J., ed. Glacier fluctuations and climatic change. Dordrccht, Kluwer Academic Publishcrs, 219-233.

Denton, G. H., M. L. Prentice and L. H. Burckle. 1990. Cainozoic history of the Antarctic ice sheet. In 'Tingry, R., ed. Geology of Antarctica. Oxford, Clarendon Press, 365-433.

Fortuin, J.P. F, and J. Oerlemans. 1990. Parameterization of the annual surface temperature and mass balance of Antarctica. Ann. Glaciol., 14, $78-84$.

Giovinetto, M. B., N. M. Waters and C. R. Bentley. 1990. Dependence of Antarctic surface mass balance on temperature, elevation, and distance to open ocean. 7. Geophys. Res., 95(1)4), 3517-3531.

Harwood, D. M. 1986. Recycled siliceous microfossils from the Sirius Formation. Antart. 7. U.S., 21(5), 101103.

Huybrechts, P. 1990. A 3-D model for the Antarctic ice sheet: a sensitivity study on the glacial-interglacial contrast. Climate Dinamicr, 5 2$), 79-92$.

Huybrechts, P. 1993. Glaciological modelling of the Late Cenozoic East Antarctic ice sheet: stability or dynamism? Geografiska Annaler, 75A 4), 221-238.

Huybrechts, P. and J. Oerlemans, 1990. Response of the Antarctic ice sheet to future greenhouse warming. Climate Dynamics, 5(2), 93-102.

Huybrechts, P., A. Letróguilly and N. Rech. 1991. The Greenland ice sheet and greenhouse warming. Palaegeogr. Palaeodimatol. Palaeoecol., 89 (4), $399-412$.

Kennett, J.P. 1977. Cenozoic evolution of Antarctic glaciation, the circum-Antarctic ocean and their impact on global palaeoceanography. 7. Geophys. Res., 82(27), 38433860.

Kennett, J. P. 1982. Marine geology. Englewood Cliffs, Prentice-Hall.

MacAycal, D. R. 1992. Irrcgular oscillations of the West Antarctic ice sheet. Vature, 359-6390), 29-32.

Mckelvey, B.C., P. N. Webb, D. M. Harwood and M. C. G. Mabin. 1991. The Dominion Range Sirius Group: a record of the late Pliocene-early Plcistocene Beardmore Glacier. In Thomson, M. R. A. and others, eds. Geological evolution of Antarctica. Cambridge, Cambridge University Press, 675-682.

Marchant, D. R., C. C. Swisher, III, D. R. Lux, 1). P. West and G. H. Denton. 1993. Pliocene paleoclimate and East Antarctic ice-sheet history from surficial ash deposits. Science, 260(5108), 667670.

Oglesby, R.J. 1989. A GCM study of Antarctic glaciation. Climate Dynamics, 3 3), 135-156.

Orvig, S. 1970 . Climates of the polar regions. In Landsberg. H. E., $q d$. World surey of climalology, Volume 14. New York, Elsevier Publishing Co.

Sugden, D. 1992. Global warming Antarctic ice sheets at risk? Iature, $\mathbf{3 5 9}(6398), 775-776$.

Van der Veen, -C.J. 1985. Response of at marine ice sheet to changes at the grounding line. Quat. Res., 24(3), 257-267.

Webb, P. N. and D. M. Harwood. 1991. Late Cenozoic glacial history of the Ross Embayment, Antarctica. Quat. Sci. Rev., 10, 215223.

Webb, P. N., D. M. Harwood, B. C. McKclicy, J. H. Mercer and L. D. Stott. 1984. Genozoic marine sedimentation and ice-rolume variation on the East Antarctic craton. Geology, 12(5), 287-291.

Webb, P.N., D. M. Harwood, B. C. Mckelvey, M. C. G. Mabin and J. H. Mercer. 1986. Late Cenozoic tectonic and glacial history of the Transantarctic Mountains. Antarct. J. U.S., 21, 99-100.

The accuracy of references in the lext and in this list is the responsibility of the author, to whom queries should be addressed. 